NOTES

\title{
Elucidation of the Stereochemical Pathway to Isotactic Poly[(methylphenylsilylene)trimethylene] from Allylmethylphenylsilane
}

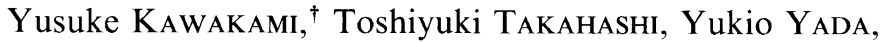 \\ and Ichiro IMAE \\ Graduate School of Materials Science, Japan Advanced Institute of Science and Technology (JAIST), \\ Asahidai 1-1, Tatsunokuchi, Ishikawa 923-1292, Japan
}

(Received June 8, 1998)

\begin{abstract}
KEY WORDS Bromosilane / Allylsilane / Optical Purity / HPLC on Optically Active Stationary Phase
\end{abstract} Optically Active Monomer / Polyaddition / Polycarbosilane / Isotacticity /

Polyaddition to give poly(carbosilane)s, well-known precursors to silicon carbide, ${ }^{1}$ via hydrosilylation was first reported by Curry, ${ }^{2}$ and we reported the polymerization of 1-allyl-3-hydro-1,1,3,3-tetramethyldisiloxane. ${ }^{3}$ Recently, liquid crystalline behavior of these polymers was reported. ${ }^{4}$ It is very important to control the stereochemistry of $\mathrm{Si}$ atom in the repeating units of these polymers in order to correlate precisely the primary structure of the polymers with such property.

Meanwhile, we reported the first example of the definite and quantitative evaluation of triad tacticity of poly[(methylphenylsilylene)trimethylene] rich in isotacticity. ${ }^{5}$ In the report, among three basic methods to synthesize optically active silicon compounds, namely, optical resolution, ${ }^{6}$ diastereoselective reduction of carbonyl compounds, ${ }^{7}$ and diastereoselective alkylation, ${ }^{8}$ we adopted the last method to synthesize the optically active allylmethylphenylsilane of moderate enantiomer excess (e.e.), and obtained the polymer by self-polyaddition of the optically active allylmethylphenylsilane (Scheme 1). However, some apparent decrease in isotacticity of the polymer $(\mathrm{S}: \mathrm{H}: \mathrm{I}=1.0: 2.0: 2.3)$ was noticed compared with the calculated value $(\mathrm{S}: \mathrm{H}: \mathrm{I}=$
$1.0: 2.0: 3.3)$ from the diastereomer excess (d.e.) of the precursor, allylbornyloxymethylphenylsilane (d.e. $=$ $60.8 \%$ ) assuming the complete stereoselectivity of each transformation to obtain the polymer from the precursor (run 4 in Table II). The decrease in isotacticity might suggest racemization in either the reduction or polymerization step. ${ }^{5}$ In order to clarify this point, we developed a new method to synthesize the allylsilane with higher e.e., and here, we report on the clarification of the stereochemical aspect of the reaction paths to give stereoregular poly[(methylphenylsilylene)trimethylene] by polyaddition. The new synthetic pathway is also included in Scheme 1.

$(R)-(+)-[(+)$-Menthyloxy] methyl(1-naphthyl)phenylsilane can be obtained by optical resolution, ${ }^{6}$ and whose d.e. was confirmed to be higher than $99.9 \%$ by HPLC on optically active stationary phase (Figure 1) and ${ }^{1} \mathrm{H}$ NMR spectrum. ${ }^{9}$ The d.e. of the brominated product, $(R)$-bromo[(+)-menthyloxy]methylphenylsilane, ${ }^{10}$ was significantly influenced by the reaction conditions. The effects of the reaction temperature on the d.e. was shown in Figure 2. Racemization is not noticed at $-64^{\circ} \mathrm{C}$. The higher the reaction temperature,

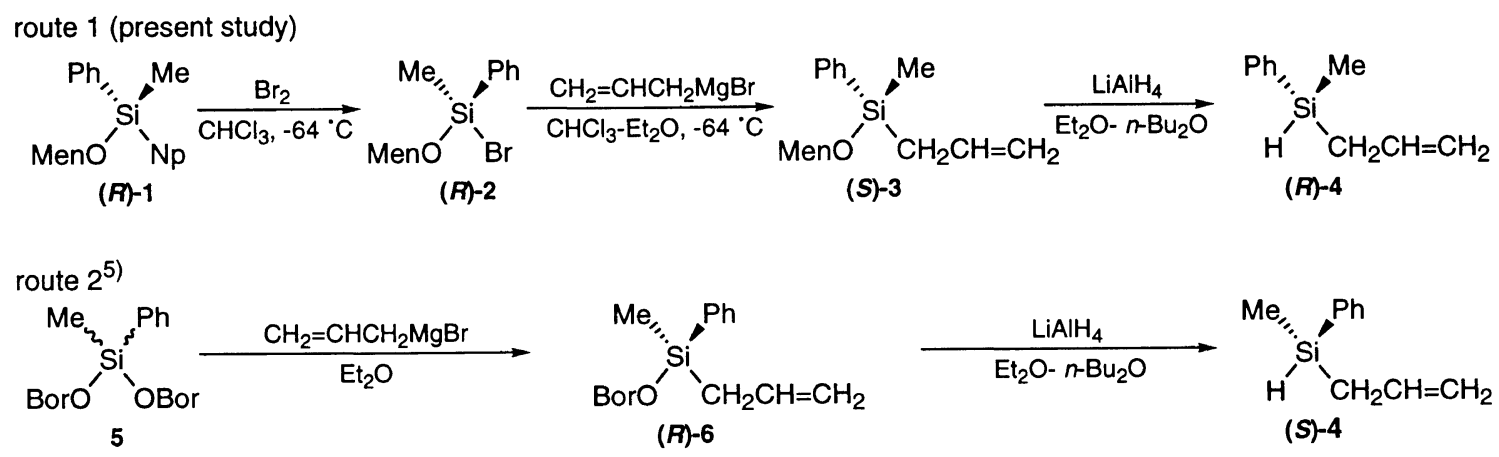

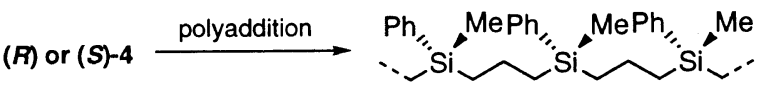

Bor $=$ bornyl, Men = menthyl, Np = 1-naphthyl

Scheme 1.

\footnotetext{
$\dagger^{\dagger}$ To whom correspondence should be addressed.
} 


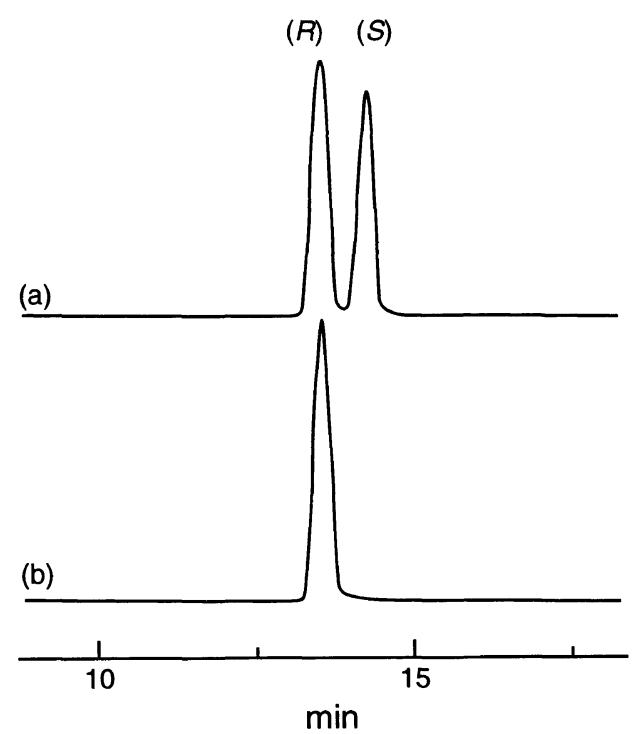

Figure 1. HPLC on optically active stationary phase of (a) racemic and (b) $(R)-[(+)$-menthyloxy $]$ methyl(1-naphthyl)phenylsilane. (Eluent, hexane; column, Chiralcel OD ${ }^{\circledR}$ [Daicel Chem. Ind. Ltd.] )

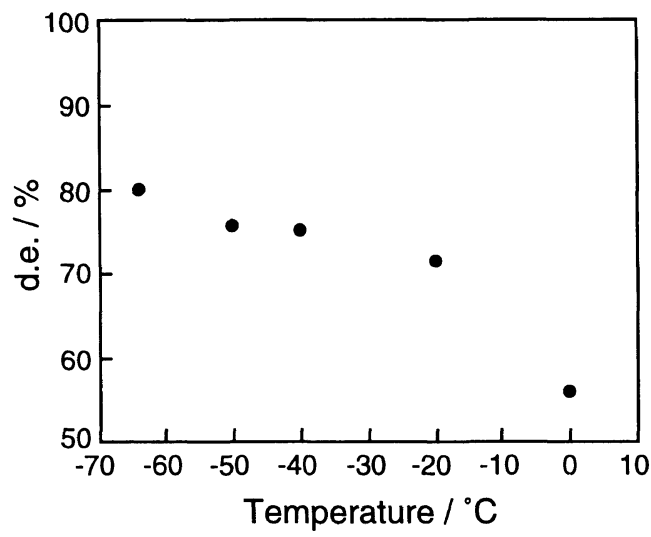

Figure 2. Dependence of d.e. of bromo $[(+)$-menthyloxy]methylphenylsilane on temperature after $3 \mathrm{~h}$ of bromination.

the easier the loss of optical activity of the product was. Chloroform was the most suitable solvent checked so far for the reaction. Remarkable racemization occurred in other solvents like chloromethane, dichloromethane, carbon tetrachloride, or benzene even at near freezing temperature of the solvent. Lower concentration $(0.1$ moldm ${ }^{-3}$ ) gave better result than higher concentration $\left(0.25 \mathrm{~mol} \mathrm{dm}^{-3}\right)$. By selecting suitable reaction conditions, $84.5 \%$ d.e. could be attained in analytical scale. Small decrease in d.e. might have occurred during NMR measurement due to the temperature elevation of the sample. The d.e. of $76.5 \%$ was attained for $(S)$ allyl $[(+)$-menthyloxy]methylphenylsilane from the bromo derivative of $78.9 \%$ d.e in synthetic scale. ${ }^{11}$ Slight decrease in d.e. might be due to some temperature elevation in transferring the reagent. Reduction by lithium aluminum hydride gave allylmethylphenylsilane having $[\alpha]_{\mathrm{D}}^{26}=+24.0$ (c 1.00 , pentane) ${ }^{12}$ This compound should have $(R)$ configuration, since reduction of alkoxysilyl group was reported to proceed with retention of $\mathrm{Si}$ stereochemistry. ${ }^{13}$ The absolute configuration of the compound already reported ${ }^{5}$ should be $(S)$, since it has the opposite sign of optical rotation. The e.e. of the 1002

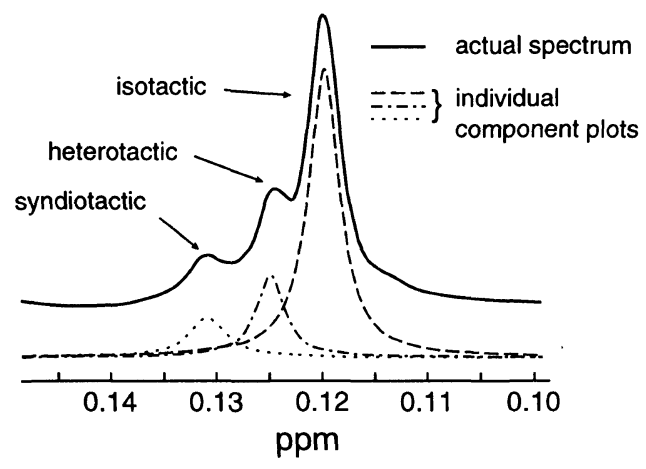

Figure 3. ${ }^{1} \mathrm{H}$ NMR spectrum of poly[(methylphenylsilylene)trimethylene $]$ obtained from the monomer having $[\alpha]_{D}^{26}=+24.0$.

Table I. Elucidation of tacticity of poly(methylphenylsilylenetrimethylene)

\begin{tabular}{|c|c|c|c|c|c|}
\hline \multirow{2}{*}{ Run } & \multicolumn{2}{|c|}{ d.e. of $3[\alpha]_{D}^{26}$ of $\mathbf{4}^{a}\left(\right.$ e.e. $\left.{ }^{b}\right)$} & \multicolumn{2}{|c|}{$\mathrm{I}: \mathrm{H}: \mathrm{S}$} & \multirow{2}{*}{$\frac{\text { e.e. of } \mathbf{4}^{\mathrm{c}}}{\%}$} \\
\hline & $\%$ & degree $(\%)$ & Calcd & Obsd & \\
\hline $1^{\mathrm{d}}$ & - & $-(0)$ & $1.0: 2.0: 1.0$ & $1.0: 2.0: 1.0$ & - \\
\hline 2 & 61 & $19.6(62)$ & $3.3: 2.0: 1.0$ & $3.5: 2.0: 1.0$ & 61 \\
\hline 3 & 76 & 24.0 & $6.6: 2.0: 1.0$ & $7.0: 2.0: 1.0$ & 77 \\
\hline $4^{\mathrm{e}}$ & $61^{f}$ & $-16.0^{\mathrm{g}}(51)$ & $3.3: 2.0: 1.0$ & $2.3: 2.0: 1.0$ & 50 \\
\hline
\end{tabular}

${ }^{\mathrm{a}} c 1.00$, pentane. ${ }^{\mathrm{b}}$ Calculated value assuming optically pure 4 has the optical rotation of $[\alpha]_{\mathrm{D}}^{26}=31.4$. ${ }^{\mathrm{c}}$ Estimated from triad tacticity. ${ }^{\mathrm{d}}$ Racemic monomer. ${ }^{\mathrm{e}}$ Ref $5 .{ }^{\mathrm{f}}$ Compound 6. ${ }^{\mathrm{g}} c 0.50$, pentane.

product could not be estimated at this point.

Polyaddition of $\mathbf{4}$ by the use of platinum 1,3-divinyl1,1,3,3-tetramethyldisiloxane complex gave reasonably high molecular weight of the polymer $\left(M_{n} \sim 10000\right.$ $\left.14000, M_{w} / M_{n}=2.6-3.0\right)$.

The $500 \mathrm{MHz}{ }^{1} \mathrm{H}$ NMR spectra of the polymer are shown in Figure 3. The methyl signals at $0.120,0.125$, and $0.131 \mathrm{ppm}$ were assigned to syndiotactic, heterotactic, and isotactic triad, respectively. ${ }^{5}$ The calculated concentration of each triad starting from the optically active monomer with $76.5 \%$ e.e. assuming complete retention of Si stereochemistry in the reduction and in the polymerization is $\mathrm{S}: \mathrm{H}: \mathrm{I}=1.0: 2.0: 6.6$. The actual concentration of each triad evaluated from Figure 3 was $1.0: 2.0: 7.0$. The ratio was $1.0: 2.0: 3.5$ starting from the compound of $60.8 \%$ e.e. (run 3 and 2 in Table I). These facts proved that there was no racemization in reduction step to synthesize allylmethylphenylsilane and polymerization. This also proved that the e.e. of $(R)$ allylmethylphenylsilane having $[\alpha]_{\mathrm{D}}^{26}=+24.0$ is $76.5 \%$. Optically pure compound might show $[\alpha]_{\mathrm{D}}^{26}=+31.4$. This value is a little larger than the recently reported value $(-28.89) .^{15}$ The e.e. of 4 estimated from the triad tacticity is reasonably well in accordance with the calculated value assuming that optically pure 4 has the optical rotation of $[\alpha]_{\mathrm{D}}^{26}=+31.4$. Thus, by elucidating the stereochemistry of polymers, the absolute configuration and e.e. could be also definitely determined for the optically active allylmethylphenylsilane, assuming the retention of stereochemistry of silicon atom in the hydrosilylation. Although we reported the possibility of racemization, ${ }^{5}$ it was clearly demonstrated that such racemization actually did not occur in the polymerization to give isotactic poly[(methylphenylsilylene)trimethy- 
lene] from allylmethylphenylsilane.

Acknowledgments. The authors are grateful to ShinEtsu Chemicals Co., Ltd. for generous donation of organosilicon compounds. This work was partially supported by a Grants-in-Aid for Scientific Research (08455438), in Priority Areas (10133220), and in Priority Areas, New Polymers and Their Nano-Organized Systems (10126222) from the Ministry of Education, Science, Sports and Culture of Japan.

\section{REFERENCES AND NOTES}

1. (a) S. Yajima, J. Hayashi, and M. Omori, Chem. Lett., 931 (1975). (b) S. Yajima, K. Okamura, and J. Hayashi, Chem. Lett., 1209 (1975).

2. J. W. Curry, J. Am. Chem. Soc., 78, 1686 (1956).

3. K. Shintani, O. Ooi, A. Mori, and Y. Kawakami, Polym. Bull., 37, 705 (1996).

4. (a) F. Koopmann and H. Frey, Makromol. Rapid Commun., 16, 363 (1995). (b) F. Koopmann and H. Frey, Macromolecules, 29, 3701 (1996). (c) S. J. Sargeant and W. P. Weber, Macromolecules, 26, 2400 (1993). (d) H. Guo, R. Volke, W. P. Weber, T. Ganicz, M. Pluta, E. B-Florjanezyk, and W. Stnczyk, J. Organometal. Chem., 444, C9 (1993).

5. Y. Kawakami, K. Takeyama, O. Ooi, and K. Komuro, Macromolecules, 31, 551 (1998). See also (a) C. X. Liao and W. P. Weber, Polym. Bull., 28, 281 (1992). (b) I. L. Rushkin and L. V. Interrante, Macromolecules, 28, 5160 (1995). (c) I. L. Rushkin and L. V. Interrante, Macromolecules, 29, 3123 (1996). (d) E. Bacqué, J-P. Pilot, M. Birot, and J. Dunogues, Macromolecules, 21, 30 (1988). (e) E. Bacqué, J-P. Pilot, M. Birot, and J. Dunogues, Macromolecules, 21, 34 (1988). (f) M. Chai, T. Saito, Z. Pi, C. Tessier, and P. L. Rinaldi, Macromolecules, 30, 1240 (1997).

6. (a) L. H. Sommer and C. L. Frey, J. Am. Chem. Soc., 81, 1013 (1959). (b) R. J. P. Corriu, G. F. Lanneau, and M. Leard, J. Organomet. Chem., 64, 79 (1974).

7. R. J. P. Corriu and J. J. E. Moreau, J. Organomet. Chem., 64, C51 (1974).

8. W. J. Richter, J. Organomet. Chem., 169, 9 (1979).

9. Diastereomeric splitting of the doublet signal due to the $\mathrm{CH}_{3}$ protons of the isopropyl group was seen at 0.47 and $0.53 \mathrm{ppm}$.

10. Solution of $(R)-(+)-[(+)$-menthyloxy $]$ methyl(1-naphthyl)phenylsilane $(4.1 \mathrm{~g}, 10.1 \mathrm{mmol}, 99 \% \text { d.e. })^{6}$ in $\mathrm{CHCl}_{3}(80 \mathrm{~mL})$ was reacted with $\mathrm{CHCl}_{3}$ solution of bromine $\left(0.5 \mathrm{~mol} \mathrm{dm}^{-3}, 20 \mathrm{~mL}\right.$, $10.0 \mathrm{mmol}$ ) at $-64^{\circ} \mathrm{C}$ for $60 \mathrm{~min}$. The d.e. of the product was determined from the integral ratio of the signals at 0.62 and $0.79 \mathrm{ppm}$ due to the $\mathrm{CH}_{3}$-protons of the isopropyl group to be $78.9 \% .{ }^{1} \mathrm{H} \mathrm{NMR}\left(\mathrm{CDCl}_{3}, \mathrm{ppm}\right): 0.62,0.79$ (two d, $3 \mathrm{H}, J=6.8 \mathrm{~Hz}$, $\mathrm{Hi}), 0.84\left(\mathrm{~s}, 3 \mathrm{H}, \mathrm{SiCH}_{3}\right), 0.85-0.93(\mathrm{~m}, 9 \mathrm{H}, \mathrm{Ha}, \mathrm{Hc}, \mathrm{Hi}), 1.07$ $(\mathrm{m}, 1 \mathrm{H}, H \mathrm{~g}), 1.27(\mathrm{~m}, 1 \mathrm{H}, H \mathrm{e}), 1.37(\mathrm{~m}, 1 \mathrm{H}, H \mathrm{~b}), 1.64(\mathrm{~m}, 1 \mathrm{H}$, $H \mathrm{~d}), 1.99\left(\mathrm{~m}, 3 \mathrm{H}, \mathrm{Hg}, \mathrm{SiCH} H_{2}\right) 2.18(\mathrm{~m}, 1 \mathrm{H}, H \mathrm{~h}), 3.79(\mathrm{~m}, 1 \mathrm{H}$, $H \mathrm{f}), 7.05-8.25$ (m, $5 \mathrm{H}$, phenyl protons).

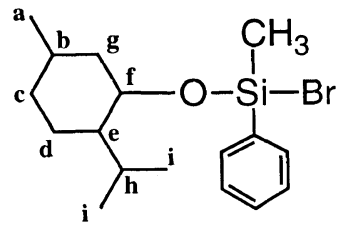

11. To a cooled (at $-78^{\circ} \mathrm{C}$ ) ether $(40 \mathrm{~mL})$ solution containing excess allylmagnesium bromide, the solution of the products of above reaction was transferred using Teflon tube at $-64^{\circ} \mathrm{C}$, and reacted for $3.5 \mathrm{~h}$. After eluting formed bromonaphthalene with hexane, the product was isolated by silica gel column chromatography with hexane : ethyl acetate $=20: 1 \quad(R f=0.2) . \quad 59.3 \%$ yield. Diastereomer excess determined from the integral ratio of the signals at 0.60 and $0.63 \mathrm{ppm}$ due to the $\mathrm{CH}_{3}$ protons of the isopropyl group was $76.5 \% .{ }^{1} \mathrm{H} \mathrm{NMR}\left(\mathrm{CDCl}_{3}, \mathrm{ppm}\right): 0.407,0413$ (two s, $3 \mathrm{H}, \mathrm{SiCH}_{3}$ ), $0.60,0.63$ (two d, $3 \mathrm{H}, J=6.8 \mathrm{~Hz}, \mathrm{Hi}$ ), $0.78-0.90(\mathrm{~m}, 9 \mathrm{H}, H \mathrm{a}, H \mathrm{c}, H \mathrm{i}), 0.98-1.07(\mathrm{~m}, 1 \mathrm{H}, H \mathrm{~g})$, $1.15-1.21(\mathrm{~m}, 1 \mathrm{H}, H \mathrm{e}), 1.24-1.34(\mathrm{~m}, 1 \mathrm{H}, H \mathrm{~b}), 1.54-1.62(\mathrm{~m}$, $1 \mathrm{H}, \mathrm{Hd}), 1.79-1.94\left(\mathrm{~m}, 3 \mathrm{H}, \mathrm{Hg}, \mathrm{SiCH}_{2}\right), 2.17-2.25(\mathrm{~m}, 1 \mathrm{H}$, $H \mathrm{~h}$ ), $3.43(\mathrm{~m}, 1 \mathrm{H}, H \mathrm{f}$ ), 4.86 (d with fine coupling, $J=9.0 \mathrm{~Hz}, 1 \mathrm{H}$, cis- $\mathrm{CH}_{2} \mathrm{CH}=\mathrm{CH}_{2}$ ), 4.90 (d with fine coupling, $J=16.5 \mathrm{~Hz}, 1 \mathrm{H}$, trans $\left.-\mathrm{CH}_{2} \mathrm{CH}=\mathrm{CH}_{2}\right), \quad 5.74-5.83\left(\mathrm{~m}, 1 \mathrm{H}, \quad \mathrm{CH}_{2} \mathrm{CH}=\mathrm{CH}_{2}\right)$, $7.34-7.41,7.57-7.60\left(\mathrm{~m}, 5 \mathrm{H}\right.$, phenyl protons). IR (neat, $\left.\mathrm{cm}^{-1}\right)$ : $3070(v$ aromatic and vinylic $\mathrm{C}-\mathrm{H}), 2956\left(v_{\mathrm{as}} \mathrm{CH}_{3}\right), 2921\left(v_{\mathrm{as}}\right.$ $\left.\mathrm{CH}_{2}\right), \sim 2870\left(v_{\mathrm{s}} \mathrm{CH}_{3}\right.$ and $\left.\mathrm{CH}_{2}\right), 1630(v \mathrm{C}=\mathrm{C})$.

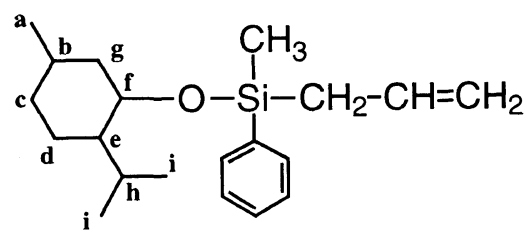

12. (S)-Allyl[(+)-menthyloxy $]$ methylphenylsilane $(2.67 \mathrm{~g}, 8.5 \mathrm{mmol})$ was reduced by lithium aluminum hydride $(0.40 \mathrm{~g}, 10.6 \mathrm{mmol})$ in diethyl ether $(10 \mathrm{~mL})$ and dibutyl ether $(12 \mathrm{~mL})$ mixed solvent at $80-90^{\circ} \mathrm{C}$ for $10 \mathrm{~h}$. The product was isolated by silica gel column chromatography (eluent: hexane) and further purified by distillation. $54-56^{\circ} \mathrm{C}(1.1 \mathrm{mmHg}) .54 .4 \%$ yield. $[\alpha]_{\mathrm{D}}^{26}=+24.0(c 1.00$, pentane). ${ }^{1} \mathrm{H}$ NMR $\left(\mathrm{CDCl}_{3}, \mathrm{ppm}\right): 0.36(\mathrm{~d}, J=3.5 \mathrm{~Hz}, 3 \mathrm{H}$, $\left.\mathrm{SiCH}_{3}\right), 1.79-1.90\left(\mathrm{~m}, 2 \mathrm{H}, \mathrm{SiCH}_{2}\right), 4.36\left(\mathrm{tq}, J_{1}=J_{2}=3.5 \mathrm{~Hz}\right.$, lH, SiH), 4.89 (d with fine coupling, $J=10.0 \mathrm{~Hz}, 1 \mathrm{H}$, cis$\mathrm{CH}_{2} \mathrm{CH}=\mathrm{CH}_{2}$ ), 4.92 (d with fine coupling, $J=17.0 \mathrm{~Hz}, 1 \mathrm{H}$, trans $\left.-\mathrm{CH}_{2} \mathrm{CH}=\mathrm{CH}_{2}\right), \quad 5.77-5.86\left(\mathrm{~m}, \quad 1 \mathrm{H}, \quad \mathrm{CH}_{2} \mathrm{CH}=\mathrm{CH}_{2}\right)$, $7.34-7.41,7.53-7.56\left(\mathrm{~m}, 5 \mathrm{H}\right.$, phenyl protons). IR (neat, $\left.\mathrm{cm}^{-1}\right)$ : $3100-3000(v$ aromatic and vinylic $\mathrm{C}-\mathrm{H}), 2964\left(v_{\text {as }} \mathrm{CH}_{3}\right), 2918$ $\left(v_{\text {as }} \mathrm{CH}_{2}\right), 2889\left(v_{\mathrm{s}} \mathrm{CH}_{3}\right), 2123(v \mathrm{Si}-\mathrm{H}), 1631(v \mathrm{C}=\mathrm{C})$.

13. L. H. Sommer, C. L. Frye, G. A. Parker, K. W. Michael, J. Am. Chem. Soc., 86, 3271 (1964).

14. Polymerizations were carried out similarly as reported by ref 5 . ${ }^{1} \mathrm{H}$ NMR and IR spectra of the polymers showed reasonable data.

15. K. Kobayashi, T. Kato, M. Unno, and S. Masuda, Bull. Chem. Soc. Jpn., 70, 1393 (1997) 